This item was submitted to Loughborough's Research Repository by the author.

Items in Figshare are protected by copyright, with all rights reserved, unless otherwise indicated.

\title{
An ontology for global production network design and reconfiguration
}

PLEASE CITE THE PUBLISHED VERSION

http://dx.doi.org/10.1007/978-3-319-21545-7_10

\section{PUBLISHER}

Springer International Publishing AG

\section{VERSION}

AM (Accepted Manuscript)

\section{PUBLISHER STATEMENT}

This work is made available according to the conditions of the Creative Commons Attribution-NonCommercialNoDerivatives 4.0 International (CC BY-NC-ND 4.0) licence. Full details of this licence are available at: https://creativecommons.org/licenses/by-nc-nd/4.0/

\section{LICENCE}

CC BY-NC-ND 4.0

\section{REPOSITORY RECORD}

Palmer, Claire, Esmond N. Urwin, Ester P. Rodriguez, Francisco S. Cid, Jose M. Pinazo-Sanchez, Sonja Pajkovska-Goceva, and R.I.M. Young. 2019. "An Ontology for Global Production Network Design and Reconfiguration". figshare. https://hdl.handle.net/2134/18943. 


\title{
An Ontology for Global Production Network Design and Reconfiguration
}

\author{
C Palmer ${ }^{1}$, E N Urwin ${ }^{1}$, E P Rodríguez ${ }^{2}$, F S Cid ${ }^{2}$, J M Pinazo- \\ Sánchez $^{3}$, S Pajkovska-Goceva ${ }^{4}$, R Young ${ }^{1}$, \\ ${ }^{1}$ Wolfson School of Mechanical and Manufacturing Engineering, Loughborough \\ University, Loughborough, Leicestershire, UK \\ \{c.palmer3, e.n.urwin, r.i.young\} @lboro.ac.uk \\ 2 ainia centro tecnológico, Parque tecnológico de Valencia, Avinguda de Benjamin \\ Franklin, 5-11, 46980 Paterna, Valencia, Spain \\ \{jmpinazo\}@ainia.es \\ ${ }^{3}$ Instituto Tecnológico de Informática, Camino de Vera s/n, Edif. 8G, Acceso B, CP 46022, \\ Valencia, Spain \\ \{cid\}@iti.es \\ ${ }^{4}$ Fraunhofer Institute for Production Systems and Design Technology IPK, Pascalstraße 8- \\ 9, 10587 Berlin, Germany \\ \{sonja.pajkovska-goceva\} @ipk.fraunhofer.de
}

\begin{abstract}
Organisations constantly seek to improve and fully exploit global production networks. This can be to provide more competitive solutions to customer requests, to exploit potential new technologies or to consider new business models based on the servitisation of products. To support such decisions requires the interchange and evaluation of information from a wide range of different and varied sources. This paper puts forward a reference ontology aimed at supporting businesses who seek to design, configure and reconfigure global production networks. The aim of this is to support interoperability between information systems within multi-domain contexts.
\end{abstract}

Keywords: product lifecycle management, global production networks, reference ontologies, interoperability, product service lifecycle systems.

\section{Introduction}

Industry, commerce and businesses have an explicit need to be profitable, competitive and survive within ever changing market, economic, political and global conditions. The development, application and adoption of technology to realise this can be one of the key aspects to success, so as to remain one step ahead of competitors. As globalisation continues at a rapid rate, the area of global supply and production networks is becoming an increasingly important one. Companies continue to seek to derive more value from their networks, focusing on the ability to rapidly configure 
and reconfigure a network of geographically diverse and disparate producers and suppliers, it therefore becomes an area that can be improved and optimised.

Problems can arise within Global Production Networks (GPN) when trying to share a wide variety of types of information and knowledge that differ between different types of businesses and domains. Furthermore, this can be compounded by trying to share this between different types of information systems, hence, the issue of interoperability between businesses and systems is a critical one that needs addressing.

One such way to alleviate this is to utilise ontologies to the build a common basis or reference ontology with which information and knowledge structures can then be built and organised so as to enable interoperability regardless of domain and information system being employed. But how can formal ontologies be developed and applied so as to better suit and serve businesses needs more effectively?

The development and application of ontologies as witnessed within the current literature is generating significant research and discussion about their potential applications and the benefit that can be gained from them. This is spread across a wide range of domains for many different purposes. Much of this research concentrates upon singular domains and does not seek to move outside of them to cross domain boundaries. There are good examples of research that try to address business needs concerning aspects of manufacturing and interoperability for organisations [1][2].

The Interoperable Manufacturing Knowledge Systems (IMKS) project is noteworthy [3], in that the research developed within it produced a manufacturing reference ontology. IMKS demonstrated how useful reference ontologies could be for enabling interoperability for sharing knowledge about manufacturing between different viewpoints and domains across a product lifecycle. As part of this, a Manufacturing Core Ontology (MCO) has been presented by Chungoora et al. [4] which, has the aim of providing support for product life cycle interoperability. Within this the use of Common Logic [5] to structure and represent the underlying semantics was justified in contrast to the use of the less expressive Web Ontology Language (OWL).

The focus of the research presented in this paper is the development and application of a production reference ontology that enables the sharing of multicontextual information to enable the configuration and reconfiguration of global production networks. The aim of this is to support the design and manufacture of product-service systems, hence different domain perspectives are of great importance.

The FLEXINET research project that is developing the ideas within this paper is described in section 2 . The production reference ontology being developed is detailed and presented within section 3 . Section 4 presents the conclusions.

\section{The FLEXINET Approach}

The approach to and premise behind the FLEXINET project is how to best design and facilitate networks of production systems that can be both flexible and interoperable. One of the main aspects within this approach is the ability to reconfigure these networks when considering and introducing new technologies. 
Production networks can sometimes be spread over vast geographical areas comprised of diverse and divergent organisations. Therefore numerous factors can influence and affect such networks. FLEXINET therefore seeks to apply cutting edge techniques to the assessment of these factors so as to enable rapid re-organisation of those networks by considering potential scenarios where benefits and disadvantages (i.e. costs and risks) can be assessed and the implications those have for configurations of production network systems and how they change over time.

The FLEXINET research project contains three key end users, each of whom are interested in understanding the impact of external demands, such as environmental regulations, on their business and most especially when related to the introduction of new product-service opportunities into their production network. Therefore, the availability, accessibility and usability of reliable data as well as the ability to use it for strategic and tactical decisions is of particular importance.

Three industrial case studies representing each of the different industrial domains have been created to develop and test the reference ontology approach. Each of these represents a different viewpoint from which, a set of end user requirements and use cases have been developed and then analysed to produce and create the reference ontology put forward in this paper. The focus of the end users is threefold, (i) firstly accelerate the ability to better meet and fulfil customer needs and requirements, (ii) secondly, ameliorate the ability to develop, introduce and move towards product servitisation and (iii) thirdly, better understand the significance of potential new technology introductions

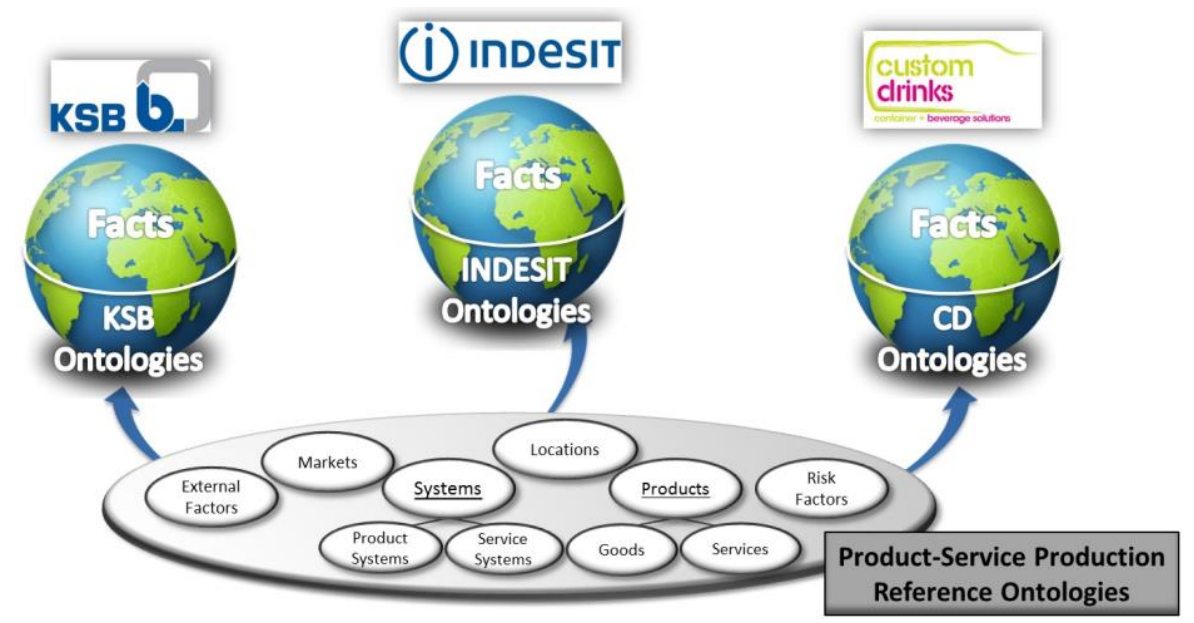

Fig. 1. Exploiting semantic models to create company specific knowledge bases.

Fig. 1 illustrates the FLEXINET approach to exploiting semantic models to create company specific knowledge bases relative to the end users. Three main software services are being actively developed to provide the environment for the assessment of risks, costs against potential network configurations. These are being supported by a reference ontology to enable the consistent representation and usage of productservice production information and knowledge across the platform. The three services are aimed at supporting strategic and tactical level decision making. The first is the 
strategic business model evaluator, as per its name it seeks to assess and evaluate cost comparisons and risk evaluations for higher level decision support, this considers strategic business interdependencies for product-service manufacture. The second of the services is the production network configurator which, is aimed at lower level tactical decisions. As its namesake is seeks to support the design and configuration of organisational and process aspects for the production network systems. The third service is that of the compliance evaluator. This studies both product and service lifecycle compliance issues when considering alterations to a production network system configuration, i.e. how do changes to a product or component affect related services in a product and vice-versa. The purpose of the underpinning reference ontology is to provide a standard basis from which information and knowledge can be represented and applied to reasoning processes for the generation of industry specific responses and solutions to the problems posed by the end user use cases.

The configuration of these service components is also aimed at improved integration between strategic and tactical business aspects to enhance the successful realisation of new business models. These configuration services, adaptable to suit multiple industrial sectors, will provide an understanding of the implications for the business of potential alternative production network configurations made necessary by product-service changes or new product-service requirements.

\section{Developing an ontology for global production networks}

FLEXINET is creating semantic models for each of the concept groups depicted in Fig. 1. But, the focus for the GPN ontology is upon production systems and more specifically, product production systems and service production systems.

The FLEXINET approach to creating a flexible re-configurable model of a GPN is to utilise a formal reference ontology. GPNs are widely applicable to a range of manufacturing areas, e.g. within FLEXINET white goods, food and drink, and pumps are considered. To enable ease of construction, flexible re-use across domains and interoperability the FLEXINET ontology is organised into five levels, as illustrated in Fig. 2. The reference ontology starts at level 1 with a generic representation, each subsequent level then becomes more specialised and domain specific until, at level 5 it represents a specific end user domain ontology. Each level inherits concepts from and provides supplementary concepts to the level above.

The Level 0 core contains highly general ontological concepts applicable to all domains and is based on the Highfleet Upper Level Ontology (ULO) [6]. This has been chosen due to the fact that Highfleet's Knowledge Frame Language (KFL) and associated Integrated Ontology Development Environment are being applied in the development of the reference ontology. The Highfleet ULO is based on the OntoClean [7] methodology. Level 1 contains the minimal set of concepts that enables any system to be represented. It is intended that level 1 stays as generic as possible so that it may be widely applicable. Importantly, synonyms of system can be process or activity. Level 2 specialises systems into designed systems and natural systems using Banathy's [8] classification. Designed systems represent anything manmade, for example manufactured goods, networks or knowledge. Natural systems represent anything natural, such as living organisms, planets and the universe. Level 3 
focuses on manufacturing business systems which requires the capability to denote decision-making. A further specialisation is provided in level 4 into Product-Service Lifecycle Systems, implemented by FLEXINET as Global production networks. Level 5 represents specialist end user GPN application areas.

The scope of FLEXINET is indicated by the white areas. At level 2 the project's scope extends into natural systems as the interaction of people with GPNs is considered. At level 4 the main area FLEXINET considers is "Produce" (producing the product-service) but the scope also overlaps into "Design" (of the global production network) and "Operate" as the operation of the product and the service needs to be considered in design. This level is linked to ISO 18629 Process Specification Language [9] and reuses the definition of process.

The concepts and relations within each of the FLEXINET levels 1-4 which are relevant to describing the concept of a GPN are illustrated graphically using the Unified Modelling Language (UML) [10] class diagrams. The full ontology is represented in Highfleet's [6] environment using KFL and ECLIF.

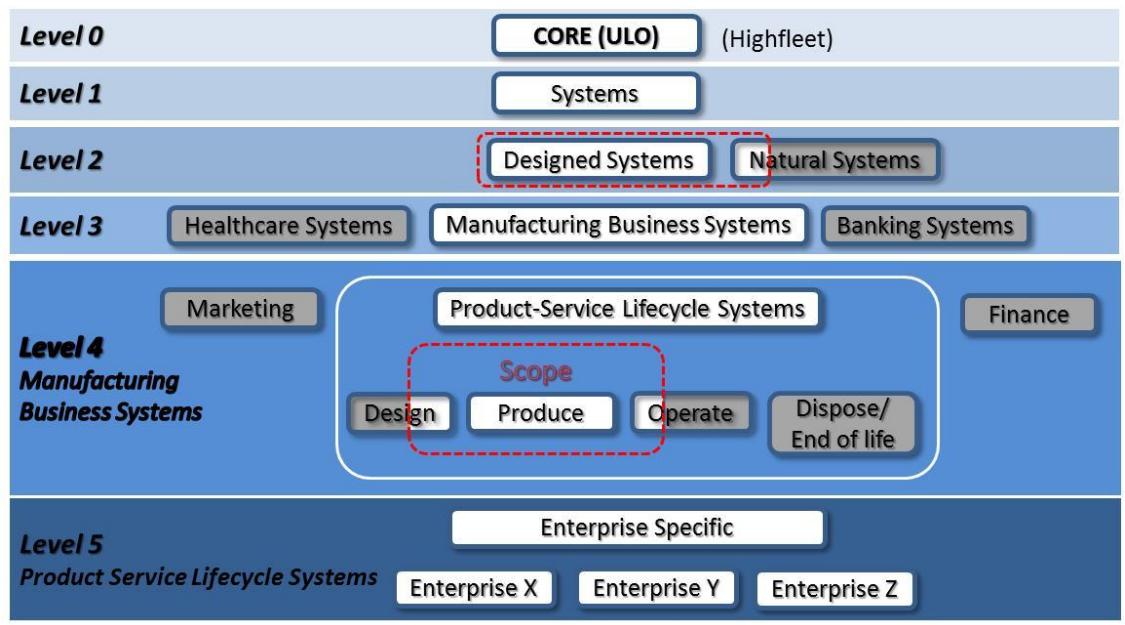

Fig. 2. The FLEXINET formal reference ontology levels.

Fig. 3 shows the complete Level 1 ontology as all of this is relevant to GPNs. The motivation for this level is to try to represent the building blocks of the Integration Definition for Function Modeling (IDEF0), i.e. function, input, output, control and mechanism (also known as resource). The top level concepts of level 1 comprise the concept 'Timespan' inherited from level 0 plus three parent concepts, 'Basic', 'Role' and 'Scenario'. A 'TimeSpan is a stretch of time beginning and ending at an instant [6]. A Basic concept [11] is independent of context, implying that its definition does not depend on another concept and an instance of a Basic always retains its identity as such. Types of Basic occurring at level 1 are Material, Information, Energy and System. A System is a group of inter-related objects played by Roles, additionally, a system provides a context for the Roles it contains (shown via the "requiresA" relation and the composition filled diamond in the Fig. 3). This developed approach looks at role-based modelling from a systems view, hence, System is the Context. 
The definition of a Role depends on a context and an instance of a Role cannot exist without a context. Four types of Role are required to represent a System: Input, Output, Resource and Control. An input represents what is brought into and is transformed or consumed by the system to produce outputs. An output represents what is brought out from or is produced by the system. A resource is used by or supports the execution of the system. A control is a condition required to produce the correct system output [12][13].

A Scenario provides a view upon a system. Scenario concepts are defined within the FLEXINET reference ontology in order to provide a method to describe multiple alternative instantiations of global production networks. As shown in Fig. 3 the playsRole relation is transitory - a Basic plays a Role within a Scenario for a certain TimeSpan. Not all systems utilise resources but all systems must have an input and an output.

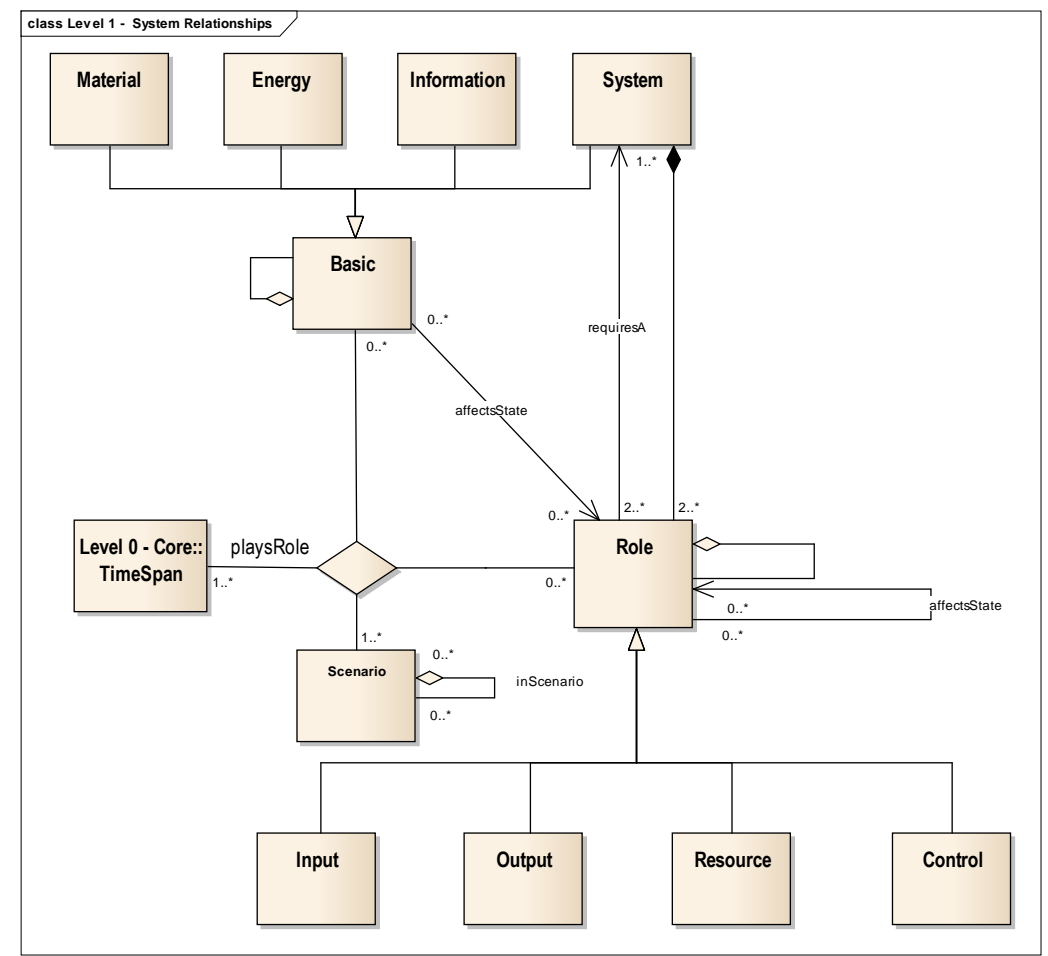

Fig. 3. Level 1 ontology graphical illustration.

The UML model states that the following constraints exist within the Level 1 ontology, those being:

- A role requires a system to provide a context.

- A system must contain an input.

- A system must contain an output.

- A system may require a resource.

- A control is also an input. (The basic playing the role of a control must play the role of an input). 


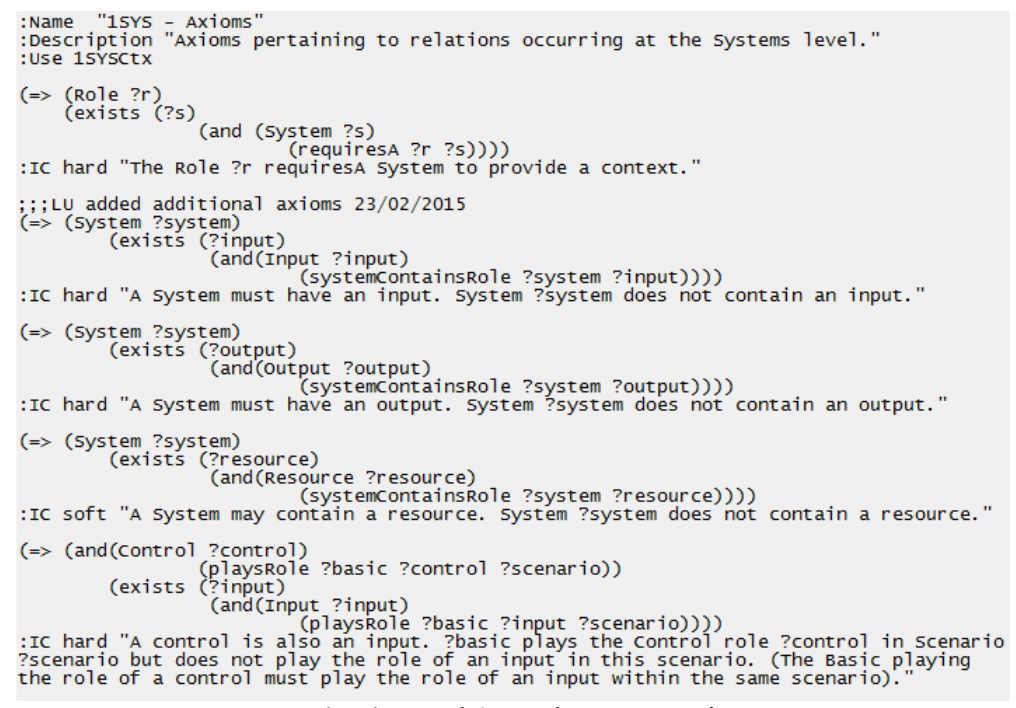

Fig. 4. Level 1 ontology constraints.

These level 1 constraints are set out in KFL code as illustrated in Fig. 4. Constraints prevent inconsistent statements. Integrity Constraints (IC) are used to check data when it is loaded into the ontology. KFL can model hard (IC hard) or soft constraints (IC soft). A hard IC must be obeyed and therefore can stop data being loaded that does not conform to the constraint. A soft IC produces a warning when data is loaded but data can still be loaded if this is ignored. An example of this in Fig. 4 is the axiom 'a role requires a system to provide a context', it states that for all roles (Role ?r), a system (System ?s) must exist (exists (?s)), the role is related to the system (requiresA ?r ?s.). It must be noted that within KFL many-to-many cardinalities are the default.

The concepts present within Level 2 Designed Systems relevant to describing a GPN are "Network", "Product", "Customer", "Supplier" and "Environ Factor". A Network is "an interconnected or interrelated chain, group, or system" [14]. FLEXINET takes the view that a Product is a process output. A Customer is a "party that receives or consumes products (goods or services) and has the ability to choose between different products and supplier" [15]. A Supplier is "a party that supplies goods or services" [15]. Environ Factors are influencing factors from a System's surroundings. For example, a production system will be influenced by surrounding production systems - a production system should not produce a product $\mathrm{X}$, if $\mathrm{X}$ is produced by another production system nearby.

Fig. 5 shows that Network is a sub-type of a System, whilst Product, Customer and Supplier are a sub-type of Role and Environ Factor is a sub-type of Information.

Defining constraints needed within Level 2 of the reference ontology are:

- A network must contain more than one system (as shown in Fig. 5).

- A basic playing the role of an output must play the role of an input to another entity (a Basic) contained within the network.

The second axiom is needed to define connectivity between the "nodes" within the network and to ensure the network model is complete. Consider an IT network: this is 
composed of several IT systems which exchange information (basics) via their inputs and outputs. Fig. 5 illustrates the inheritance from Level 1 for the concepts System, Role and Information. This inheritance from 'Level1 - Systems::' is the entire Level 1 set of concepts that includes 'system'.

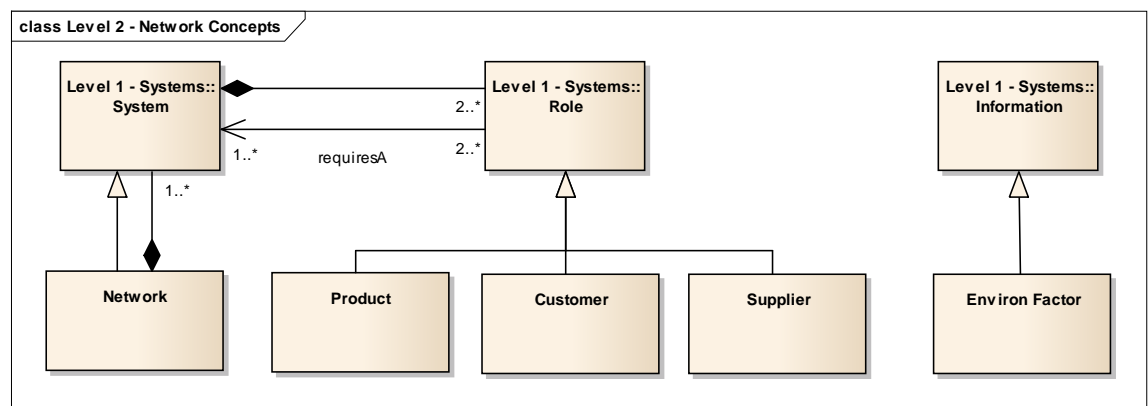

Fig. 5. Level 2 Designed Systems Ontology concepts relevant to GPNs.

Modelling manufacturing business systems at Level 3 requires the ability to capture manufacturing processes and decisions. Manufacturing processes are modelled using the Basic System. Concepts introduced at Level 3 to model GPNs are the roles Manufacturer and Manufactured Product (which inherits from the Level 2 Product concept as shown in Fig. 6); Manufacturing Network (which inherits from the Level 2 Network concept); and the basic, Gateway. A Manufacturer is an "Entity that makes a good through a process involving raw materials, components, or assemblies, usually on a large scale with different operations divided among different workers" [15]. A Manufactured Product is a product that exploits or consumes a raw material. A Manufacturing Network is a Network which is concerned with the design, finance or production of a Manufactured Product. A Gateway is an abstract concept whose sub-types (shown in Fig. 7) are able to capture process decisions.

The composition filled diamond in Fig. 6 indicates that the following constraint exists at Level 3:

- A Manufacturing Network must contain a Manufactured Product.

This constraint implies that a Manufacturer is required to manufacture the Manufactured Product.

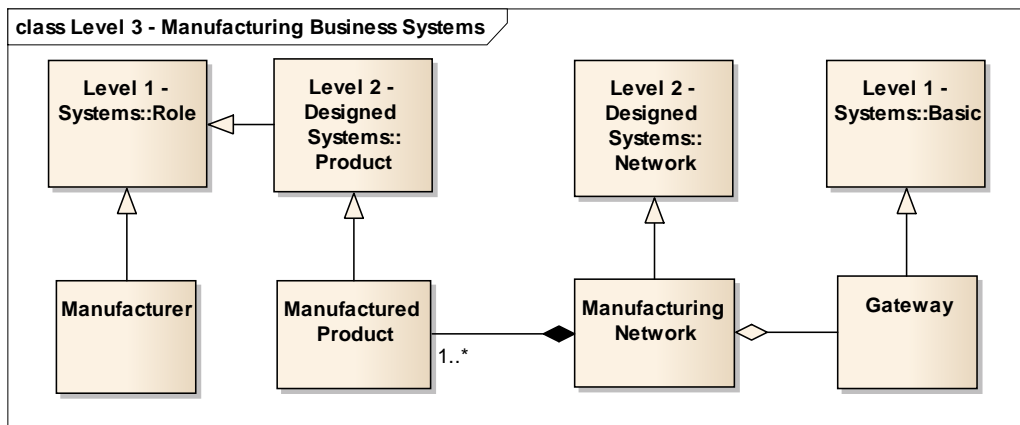

Fig. 6. Level 3 Manufacturing Business Systems Ontology concepts relevant to GPNs. 
If process decisions need to be modelled within a Manufacturing Network it will contain Gateways, hence, it is necessary to represent decision oints with multiple paths thereafter. A Gateway is a specialised type of Basic with at least one input and one output, based on the BPMN Gateway Process Element [16]. Fig. 7 shows this constraint and the Gateway subtypes. Gateway has six sub-types: Diverging (an "opening AND" or a fork), Converging (a "closing AND" or a join), Inclusive Diverging (an "opening OR"), Inclusive Converging ("closing OR"), Exclusive Diverging ("opening XOR" or a branch) and Exclusive Converging ("closing XOR" or a merge).

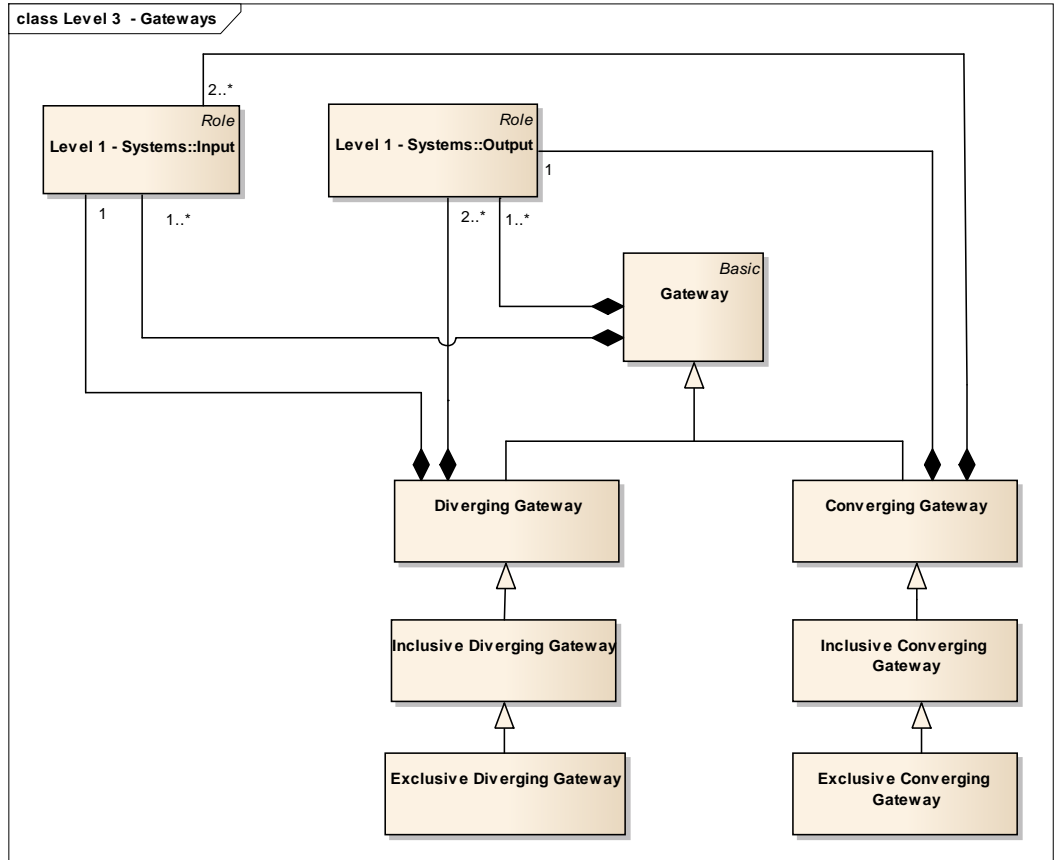

Fig. 7. Level 3 Gateway Concepts.

Level 3 constraints required to describe a Gateway are:

- A Gateway must contain an input and an output.

- A Diverging Gateway must contain only one input and 2 or more outputs (shown in Fig. 7 using multiplicity constraints on the composition associations).

- A Converging gateway must contain 2 or more inputs and only one output (shown in Fig. 7).

- An Inclusive Diverging Gateway must have a Boolean condition (for example, "If supplementary documents are needed"). An output should be provided for the case where the condition cannot be satisfied to prevent the network blocking at the gateway.

- An Inclusive Converging Gateway must have a Boolean condition. 
- An Exclusive Diverging Gateway must have more than one Boolean condition, of which only one can evaluate to true. For example, only it is only possible for one of the conditions "If the material passes the quality control top grade" or "If the material does not pass the quality control top grade" to occur within a process.

- An Exclusive Converging Gateway must have two opposing Boolean conditions (i.e. only one condition within the XOR gateway is activated).

Level 4 (see Fig. 8) introduces the concepts Production Network, Global Production Network (GPN), Producer, Start? and End?. A Production Network is a specialism of a Manufacturing Network which is concerned with producing a Manufactured Product. A Global Production Network is defined here as a specialism of a Production Network which contains Roles played by globally dispersed Systems. A Producer is "a person or business enterprise that generates goods or services for sale" [14] and is a sub-type of Role. A Production Network is concerned with a production process which requires a Start and an End. An End prevents infinite loops forming in the Production Network by providing a breakpoint. A Production Network is defined with the following constraints (shown in Fig. 8):

- A Production Network must have a Start Event and an End Event.

- A Production Network must contain the role Producer.

- A Production Network will contain the role Supplier.

- A Production Network will contain the role Customer.

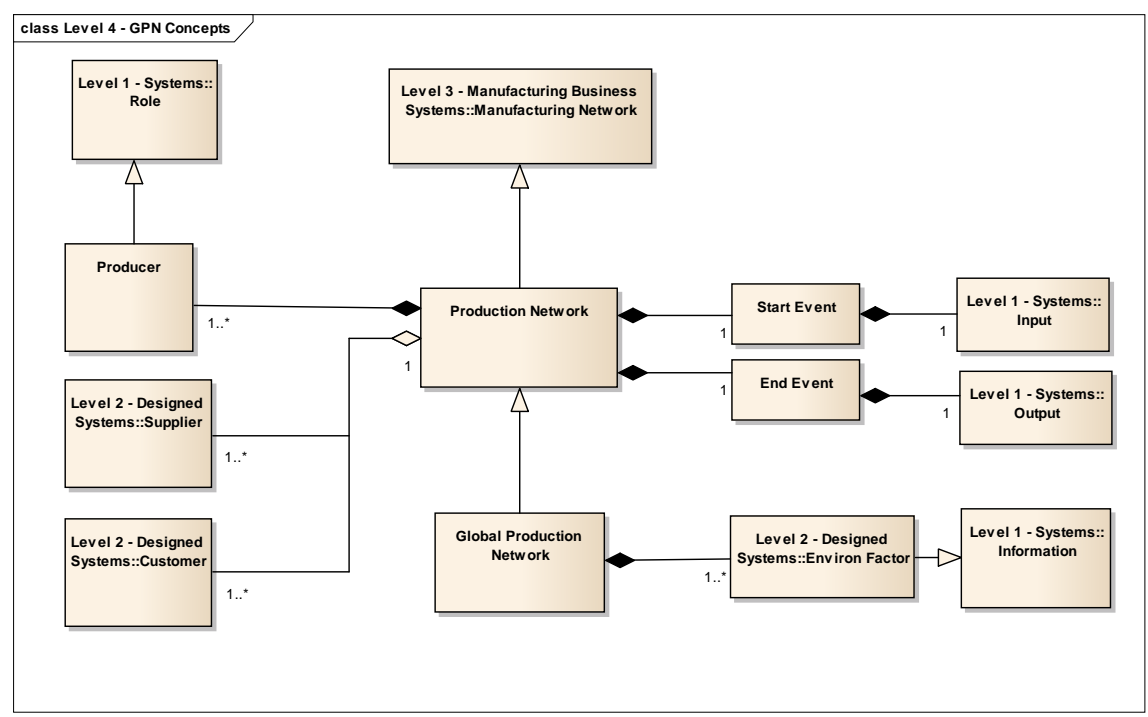

Fig. 8. Level 4 Product-Service Lifecycle Systems concepts relevant to GPNs.

Constraints describing Start and End are as follows:

- A Start Event must contain only one output. (The output role is played by the trigger for the Production Network).

- An End Event must contain only one input. 
- The Basic playing the role of a Product within a Production Network must also play the role of an Input to an End of the Production Network.

The last constraint states that one of the outputs in a Production Network must be a product, as this is what a Production Network is concerned with producing.

To express the global specialisation of a GPN the following constraint is needed:

- A System playing a role within a GPN must have Environ Factors.

Organisations form member systems within GPNs. As members within a GPN are influenced by other members and also factors external to the GPN there is a need to model Environ Factors within a GPN. For example, an organisation within a GPN will be influenced by the reliability of the other GPN member organisations which supply it and also by external markets for the product of the GPN.

\section{Conclusions}

This paper has presented research focused upon the development of a reference ontology to serve and answer industrial end users' needs. It has been created using industrial information and knowledge from three different domains using a multiple case study approach. Businesses frequently deal with uncertainty when planning for, developing and producing products and services. The FLEXINET approach, underpinned by the reference ontology, is to offer decision support tools to analyse different scenarios to consider what-if questions to help users derive potential solutions to those questions. The GPN reference ontology is a formal multiple domain representation of the concepts, relationships and axioms that constitute complex global production networks and the factors that influence. Whilst presented in this paper utilising the UML formalism, it has been developed using the Common Logic based Highfleet Knowledge Framework Language.

A number of questions concerning ontology development and application to help businesses are influencing further work. They are (i) to what extent can a reference ontology be developed to sufficiently represent three different manufacturing sectors, (ii) if a reusable reference ontology can be developed, to what extent does it reduce the cost and time of developing knowledge systems, (iii) can a method be developed to effectively specialise concepts from generic to specific levels within a production reference ontology, (iv) what are the key concepts and relationships that need to be defined within the reference ontology and (v) to what extent can the rules and constraints be defined generically as opposed to for each business?

The next steps within the FLEXIENT project will be the testing of the developed reference ontology by applying the industrial use cases. The results of these tests will be evaluated against the end user requirements to derive outcomes. This will provide excellent feedback to the applicability of the developed ontology, the benefit that can be obtained from the application to multiple business domains and the aspects to focus upon for further iterative improvement and development. 


\section{Acknowledgements}

The research leading to these results has received funding from the European Community's $7^{\text {th }}$ Framework Programme under grant agreement $n^{\circ}$ NMP2-SL-2013608627.

\section{References}

1. Young, R.I., Gunendran, A.G., Cutting Decelle, A-F., Gruninger, M.: Manufacturing knowledge sharing in PLM: a progression towards the use of heavy weight ontologies. International Journal of Production Research, 45(7), pp. 1505--1519 (2007)

2. Panetto, H., Goncalves, R., Molina, A.: Enterprise Integration and Networking: theory and practice. Annual Reviews in Control, 36(2), pp. 284--290 (2012)

3. Chungoora, N., Cutting-Decelle, A-F., Young, R.I.M., Gunendran, G., Usman, Z., Harding, J.A., Case, K.: Towards the ontology-based consolidation of production-centric standards. International Journal of Production Research, 51(2), pp. 327--345 (2013)

4. Chungoora, N., Young, R.I.M., Gunendran, G., Palmer, C., Usman, Z., Anjum, N.A., Cutting-Decelle, A.F, Harding, J.A., Case, K.: A model-driven ontology approach for manufacturing system interoperability and knowledge sharing. Computers in Industry, 64, pp. 392--401 (2013)

5. ISO/IEC 24707:2007. Information technology - Common Logic: a framework for a family of logic-based languages. Genève, Switzerland (2007)

6. Highfleet Ontology Library Reference. Baltimore, MA: HIGHFLEET Inc. (2014)

7. Guarino, N., Welty, C.A.: An Overview of OntoClean, Handbook on Ontologies International Handbooks on Information Systems, pp 151--171 (2013)

8. Banathy, B.H.: A systems view of education: Concepts and principles for effective practice. Educational Technology (1992)

9. ISO 18629-1:2004, Industrial automation systems and integration -- Process specification language -- Part 1: Overview and basic principles. Genève, Switzerland (2004)

10. OMG, 2012 OMG unified modeling language (OMG UML), superstructure and infrastructure version 2.4.1, http://www.omg.org/spec/UML/2.4.1/

11. Mizoguchi, R., Kozaki, K., Kitamura, Y.: Ontological analyses of roles. In: Proceedings of the Federated Conference on Computer Science and Information Systems, IEEE, pp. 489-496 (2012)

12. Athena, Advanced Technologies for Interoperability of Heterogeneous Enterprise Networks and their Application FP7 no 507849, 2006, POP* Revised Framework - Work Package A1.8. Amerigo, Supply Chain Mapping, Program Profit - IBB 2007, Zwischenberciht (2007)

13. PUBs, F.: Integration definition for function modelling (IDEF0). Federal information processing standards publication, 183 (1993)

14. Collins Dictionaries, http://www.collinsdictionary.com/dictionary/english

15. BusinessDictionary.Com, 2015, http://www.businessdictionary.com/

16. Object Management Group (OMG), 2011, Business Process Model and Notation (BPMN) V2.0, http://www.omg.org/spec/BPMN/2.0/ 